\title{
'Breaking It Down': Patient-Clinician Communication and Prenatal Care Among African American Women of Low and Higher Literacy
}

Ian Bennett, $M D, P b D^{1,2}$

Julia Switzer, BA ${ }^{1}$

Abigail Aguirre, $M P A^{1}$

Kelley Evans, $M A^{2}$

Frances Barg, $\mathrm{PhD}^{1,3}$

'Department of Family Practice and Community Medicine, University of Pennsylvania, Philadelphia, $\mathrm{Pa}$

${ }^{2}$ Graduate School of Education, University of Pennsylvania, Philadelphia, $\mathrm{Pa}$

${ }^{3}$ Department of Anthropology, University of Pennsylvania, Philadelphia, $\mathrm{Pa}$

\&is

MORE ONLINE

www.annfammed.org

\begin{abstract}
PURPOSE Low literacy has been associated with poor medical adherence, but its role in maternal care utilization has not been explored.

METHODS We undertook a concurrent mixed methods study among 202 African American women of low ( $\leq 6$ th grade) and higher literacy receiving Medicaid. Poor use of prenatal care was defined by (1) starting care after the first trimester and (2) inadequate care utilization according to the Adequacy of Prenatal Care Utilization Index (APNCU). Participant-derived themes regarding prenatal care and care utilization were identified and explored through individual interviews (free listing and cultural consensus analysis; $n=40$ ), and 4 confirmatory focus groups stratified by literacy.
\end{abstract}

RESULTS Thirty-three women (16\%) had low-literacy levels, 120 (61\%) women started prenatal care after the first trimester, and 101 (50\%) had inadequate utilization of prenatal care. Neither measure varied by literacy $(P>.05)$. Cultural consensus analysis identified a single prenatal care factor that was comprised of 9 items, shared by women of low and higher literacy (eigenvalue 0.881 , SD 0.058). Focus groups confirmed these items among participants from both literacy groups. Communication with clinicians was a central theme linking all of the factor items. Effective communication, exemplified by "breaking it down," was described as encouraging, whereas ineffective communication discouraged use of care.

CONCLUSION Women who had both low- and higher-literacy skills had high rates of poor prenatal care utilization and reported that communication with clinicians influenced their use of prenatal care. Improving the clarity of communication by breaking down information into simple parts should be a priority for prenatal clinicians.

Ann Fam Med 2006:4:334-340. DOI: 10.1370/afm.548.

\section{INTRODUCTION}

Conflicts of interest: none reported

\section{CORRESPONDING AUTHOR}

Ian Bennett, $\mathrm{MD}, \mathrm{PhD}$

Department of Family Practice and Community Medicine

University of Pennsylvania

3400 Spruce Street

2nd Floor Gates Building

Philadelphia, PA 19104

ian.bennett@uphs.upenn.edu
$\mathrm{D}$ espite efforts to improve utilization of maternal health services, vulnerable populations are more likely to enter prenatal care late or receive no care. ${ }^{1}$ In 2002 African American women were 3 times as likely as white women to have no prenatal care. ${ }^{2}$ Although increasing the utilization of prenatal care alone will not eliminate the wide disparities in maternal-child health outcomes experienced by African American women, reducing obstacles to prenatal care that may contribute to improved utilization of postpartum and pediatric care is an important goal of the US health system. ${ }^{3-8}$

Low literacy has been proposed as a possible mediator of health dis- 
parities, in part through its effects on health care utilization, yet we are not aware of any research that has explored the role of low literacy as an obstacle to utilization of prenatal care. ${ }^{9}$ What is known is that women with less than a high school education, a risk factor for low literacy, are less likely to initiate early prenatal care. ${ }^{1,10,11}$ Literacy is also a critical skill needed for health literacy, which involves both health care navigation and health decision-making skills. ${ }^{9}$ Studies that identify obstacles to care faced by women of low literacy are needed to guide interventions to improve health care delivery to this vulnerable group. We assessed utilization of prenatal care and explored perceived obstacles to that care among a group of African American women with low- and higher-literacy skills who recently gave birth and were receiving Medicaid.

\section{METHODS}

We used a concurrent mixed methods (quantitative and qualitative, weighted equally) study design (Figure 1). A concurrent rather than sequential approach was chosen to minimize the time between the prenatal period, the focus of the study, and data collection. This strategy also minimized bias against women who were more difficult to follow up for longer periods. Individual enrollment interviews, chart abstraction, free listing, and follow-up focus group interviews were carried out over a 14-month period from July 2002 to September 2003. Permission to conduct this research was granted by the University of Pennsylvania Institutional Review Board.

\section{Sample}

Women $(\mathrm{n}=237)$ from an urban Medicaid obstetric practice at the University of Pennsylvania were approached for enrollment sequentially within 48 hours of giving birth (before leaving the hospital) by 3 white female research assistants from May 2002 to November 2002. Each woman received a low-literacy guide to pediatric care and 4 children's picture books to be read to the infant as an incentive to participate in the study.

\section{Variables}

All survey questions were asked during individual face-to-face interviews. Literacy was esti- mated at recruitment using the Rapid Estimate of Adult Literacy in Medicine (REALM). ${ }^{12,13}$ Low literacy was defined as $\leq 6$ th grade reading level, because poor medical adherence and outcomes have been associated with this REALM score. ${ }^{14}$ Poor prenatal care was defined as (1) initiation of prenatal care after the first trimester (12 weeks' gestational age), and (2) inadequate care as assessed by the Adequacy of Prenatal Care Utilization Index (APNCU). ${ }^{15}$ The APNCU index assesses adherence to the standard and most common recommended schedule of prenatal care visits (in the United States) using 2 dimensions: month of initiation of care, and total number of visits adjusted for gestational age at delivery. Although visit characteristics were reported as a range of 4 outcomes (from inadequate to adequate plus), we limited our analysis to the inadequate category, which widely deviates from standard practice ( $<50 \%$ of the recommended visits and/or care initiated after the fourth month of gestation). Care utilization data were abstracted directly from antepartum charts cross-checked with an electronic clinic scheduling and billing database for prenatal visits. When inconsistencies were found, the higher number of visits was used to minimize underestimation.

\section{Free Listing and Cultural Consensus Analysis}

Free listing is a qualitative method used here to explore the topic of prenatal care. A randomly chosen group of participants $(n=40$; low literacy $=9$, and higher

\section{Figure 1. Study procedures and timeline.}

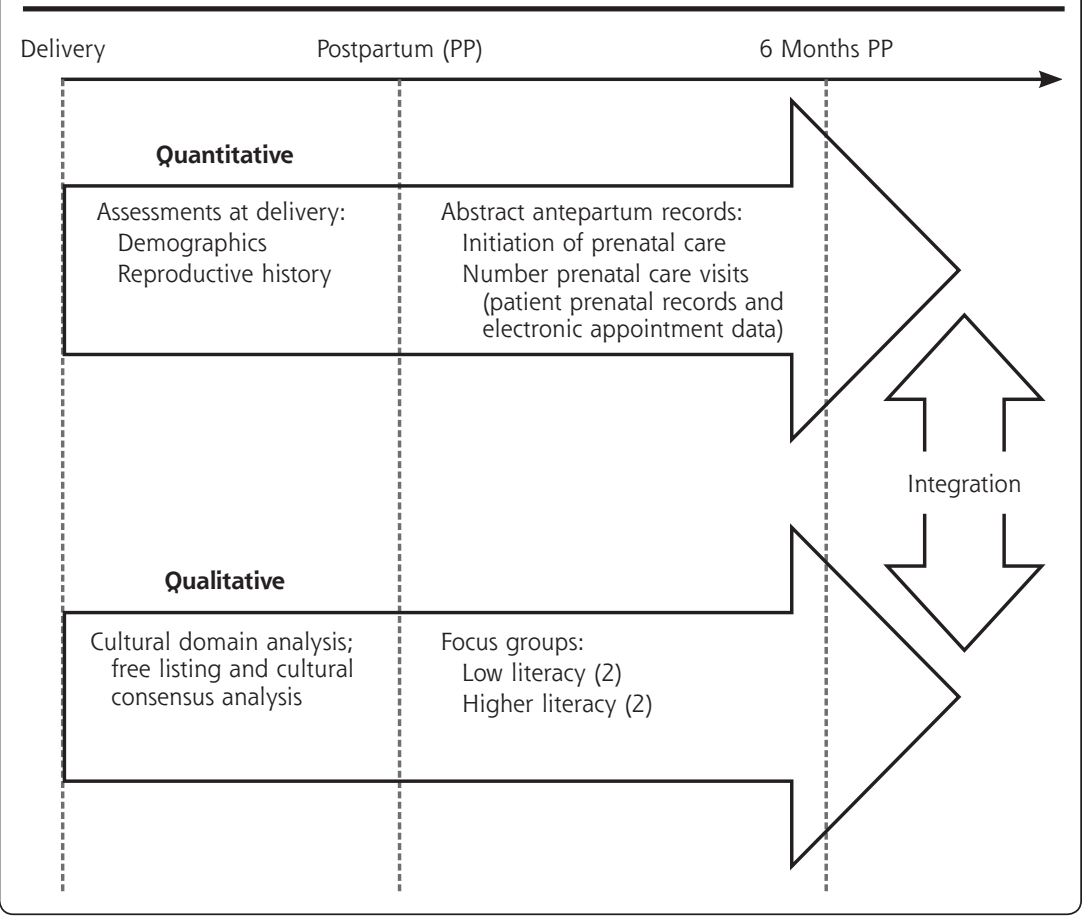


literacy $=31)$ carried out a free-list task $(<10$ minutes) during the enrollment interview regarding their experience of prenatal care. Women were asked to list up to 10 words or short phrases for "things that you think about when going to the doctor when you are pregnant." Free listing and the subsequent cultural consensus analysis, together sometimes referred to as cultural domain analysis (CDA), determine how members of a group define a particular cognitive domain of experience or understanding (additional discussion of this method can be found in Supplemental Appendix 1,

available online-only at http://www.annfammed.

\section{Focus Groups}

Focus groups were carried out to confirm and explore the items identified by the CDA. All women having low-literacy skills ( $\leq 6$ th grade) and an equal number of women with higher-literacy skills ( $\geq 9$ th grade), matched by age and postpartum month, were invited to participate in the focus group interviews. A level of higher literacy different from those in the other analyses was chosen to enhance any contrasts based on literacy. Four separate 90-minute focus groups were conducted (2 for low literacy and 2 for higher literacy). Participants were unaware that literacy level was a selection criterion. A focus group guide (Supplemental Appendix 2, available

online-only at http://www.annfammed.org/cgi/ discussion of obstacles to prenatal care with probes for items raised in the cultural domain analysis if they did not come up spontaneously. A white female focus group leader moderated all sessions with 2 female assistants (1 white and 1 African American). Participants received $\$ 35$ as an incentive. Focus groups sessions and debriefing discussions immediately after the focus groups were tape recorded and transcribed.

\section{Analysis}

Differences in the categorized demographic and descriptive variables, as well as in the initiation of care and adequacy of care index (inadequate vs all other categories) between the 2 literacy groups, were assessed using the $\chi^{2}$ test $(P<.05)$ (SPSS version 12, SPSS Inc, Chicago).

\section{Free Lists and Cultural Consensus Analysis}

Free lists of words and short phrases were examined for redundancy, and synonyms were grouped. Free lists were then analyzed using the consensus analysis function in Anthropac software. ${ }^{18}$ Consensus analysis yields a knowledge score and eigenvalues for the first and second factors that are created, which are then used to determine whether there is an underlying pattern of agreement among respondents. ${ }^{19}$ A cultural consensus model tests the extent to which knowledge is shared among subjects, provides an estimate of cultural congruence (the extent to which an individual's perceptions about the topic agrees with others) for each person in the sample, and provides estimates of the content of the cultural domain under consideration. ${ }^{20}$ Salient or the most important words for the group are determined by weighting the frequency and order that a word or phrase is mentioned. Free lists were first analyzed for the entire group of 40 women and then separately for women in the higher-literacy group.

\section{Focus Group Interviews}

The CDA method produces a list of words and short phrases that represent the "skeletal outline" of a domain. ${ }^{21}$ Three investigators familiar with the focus groups carried out the focus group analysis using a grounded theory approach to explore items raised in the $\mathrm{CDA}^{22}$ to confirm the factor items produced by the CDA, and to fill in the meaning and relationships of items in this domain. The grounded theory approach involves development of theories about what is occurring in the data as they are collected. Field notes taken by the investigators during the interviews were used to generate 7 broad thematic categories from the discussions related to the CDA factor items and obstacles to care for initial coding: obstacles to using care, motivations for using care, communication with clinicians, sources of information, emotions, preparation for visits, and other. Finer coding within these themes emerged with close reading of the transcripts. Coding and analysis were carried out with the aid of the QSR N6 qualitative software package (QSR International). Coding consensus was achieved through discussions at weekly meetings. All coding was done without attention to literacy.

\section{Synthesis of Mixed Methods Results}

Quantitative assessment of actual care utilization and qualitative assessment of participant-derived beliefs relevant to utilization were collected to triangulate results from these 2 methods and to enhance the overall explanatory result of the study. ${ }^{23}$ Although the qualitative methods were carried out in sequence (CDA and then focus groups), the qualitative and quantitative components of the study were carried out independently and synthesized at the time of analysis (Figure 1).

\section{RESULTS}

Of the 237 women approached for study enrollment, 25 declined to participate (90\% participation). Women were excluded from the analysis because of non-African 
American race (their small numbers precluded meaningful comparison; $\mathrm{n}=23$ ) or missing prenatal records $(\mathrm{n}=$ 12), resulting in a final sample of 202. Of the 202 study participants, 33 (16\%) had low-literacy skills (Table 1). One hundred twenty-one participants (61\%) initiated care after the first trimester, and 101 (50\%) had inadequate prenatal care. Women with low-literacy skills $\left(\leq 6^{\text {th }}\right.$ grade) were not significantly more likely than women with higher-literacy skills ( $\geq 7^{\text {th }}$ grade) to have their first prenatal visit after the first trimester $(P=.257)$ or inadequate prenatal care $(P=.341)$. Post-hoc power analysis indicated $80 \%$ power to detect an absolute difference of approximately 0.35 in the proportion having poor use of care by either measure (we observed a difference of 0.11 and 0.9 , respectively).
Cultural Domain Analysis (CDA)

Free listing and cultural consensus analysis were carried out with 40 participants (9 low literacy, 31 higher literacy). Salient terms for "things that you think about when going to the doctor when you are pregnant" included (from most to less salient) "is everything ok?" "long wait," "questions," "needles" (blood tests and intravenous catheters), "weight," "heart beat," "ultrasound," "baby's health," and "tests" (Table 2). The same terms were salient when the lists from women with low-literacy skills were excluded. Cultural consensus analysis returned a single factor (eigenvalue 0.881 , SD 0.058), with a high degree of shared knowledge (0.863, SD 0.061) among participants of both low and higher literacy.

\begin{tabular}{|c|c|c|c|c|}
\hline Variable & $\begin{array}{l}\text { Low Literacy } \\
\begin{array}{c}\leq 6 \text { th Grade } \\
n=33\end{array}\end{array}$ & $\begin{array}{c}\text { Higher } \\
\text { Literacy } \\
\geq 7 \text { th Grade } \\
\mathbf{n}=169\end{array}$ & $\begin{array}{c}\text { Total } \\
\mathrm{n}=202 \\
\end{array}$ & $P$ Value \\
\hline \multicolumn{5}{|l|}{ Age } \\
\hline $15-25$ y & $25(76)$ & $121(72)$ & $146(72)$ & .625 \\
\hline $26-42$ y & $8(24)$ & $48(28)$ & $56(28)$ & \\
\hline Years of school, mean (SD) & $10.6(1.2)$ & $11.7(1.8)$ & $11.6(1.8)$ & $<.001$ \\
\hline Medicaid insurance & $33(100)$ & $169(100)$ & $202(100)$ & \\
\hline \multicolumn{5}{|l|}{ Parity (total births) } \\
\hline 1 & $13(39)$ & $38(23)$ & $51(25)$ & .105 \\
\hline $2-4$ & $14(42)$ & $100(59)$ & $114(56)$ & \\
\hline$>5$ & $6(18)$ & $31(18)$ & $37(18)$ & \\
\hline Low birth weight $(<2,500 \mathrm{~g})$ & $1(3)$ & $15(11)$ & $16(8)$ & .162 \\
\hline Preterm delivery (<36 wk) & $12(36)$ & $29(17)$ & $41(20)$ & .245 \\
\hline Cesarean delivery & $5(14)$ & $25(18)$ & $30(17)$ & .663 \\
\hline $\begin{array}{l}\text { First prenatal visit after } \\
\text { first tirmester }\end{array}$ & $23(70)$ & $97(59)$ & $120(61)$ & .257 \\
\hline $\begin{array}{l}\text { Inadequate prenatal care } \\
\text { utilization (APNCU) }\end{array}$ & $19(58)$ & $82(49)$ & $101(50)$ & .341 \\
\hline
\end{tabular}

\section{Focus Groups}

Four focus groups were completed: 2 with low-literacy participants $\left(\leq 6^{\text {th }}\right.$ grade $\left._{i} \mathrm{n}=8\right)$ and 2 with higher-literacy participants $\left(\geq 9^{\text {th }}\right.$ grade $; \mathrm{n}=10$; Table 3 ). The items identified in the CDA were confirmed to be salient to members from all focus groups, as indicated by either having been introduced spontaneously or confirmed when raised as probes. Although the individual items identified in the CDA address a range of prenatal topics, including the assessment of well-being of the mother and baby, the inconveniences of prenatal care (long wait), patient-clinician communication (questions), and medical testing, communication with clinicians emerged as a cen-

Table 2. Free List and Consensus Analysis

\begin{tabular}{|c|c|c|c|c|c|c|c|c|c|}
\hline \multirow[b]{2}{*}{$\begin{array}{l}\text { Item Ranked } \\
\text { by Salience* }\end{array}$} & \multicolumn{3}{|c|}{ Percent of Respondents } & \multicolumn{3}{|c|}{$\begin{array}{l}\text { Average Position } \\
\text { on the Freelists }\end{array}$} & \multicolumn{3}{|c|}{ Smith's Saliency Score } \\
\hline & $\begin{array}{c}\text { Low } \\
\text { Literacy } \\
(n=9)\end{array}$ & $\begin{array}{c}\text { Higher } \\
\text { Literacy } \\
(n=31)\end{array}$ & $\begin{array}{c}\text { All } \\
(n=40)\end{array}$ & $\begin{array}{c}\text { Low } \\
\text { Literacy } \\
(n=9)\end{array}$ & $\begin{array}{c}\text { Higher } \\
\text { Literacy } \\
(n=31)\end{array}$ & $\begin{array}{c}\text { All } \\
(n=40)\end{array}$ & $\begin{array}{c}\text { Low } \\
\text { Literacy } \\
(n=9)\end{array}$ & $\begin{array}{c}\text { Higher } \\
\text { Literacy } \\
(n=31)\end{array}$ & $\begin{array}{c}\text { All } \\
(n=40)\end{array}$ \\
\hline Everything ok & 56 & 26 & 33 & 2.2 & 3.50 & 3.00 & .399 & .180 & .229 \\
\hline Long wait & 22 & 32 & 30 & 1.0 & 4.30 & 3.75 & .222 & .181 & .190 \\
\hline Questions & 33 & 29 & 30 & 3.0 & 4.67 & 4.25 & .241 & .153 & .179 \\
\hline Needles & 22 & 26 & 25 & 4.5 & 2.88 & 3.20 & .095 & .192 & .167 \\
\hline Weight & - & 29 & 23 & - & 3.89 & 3.89 & - & .190 & .147 \\
\hline Heart beat & 11 & 19 & 18 & 2.0 & 3.00 & 2.86 & .056 & .150 & .138 \\
\hline Ultrasound & 11 & 19 & 18 & 5.0 & 3.33 & 3.57 & .056 & .141 & .122 \\
\hline Baby's health & 22 & 23 & 23 & 5.0 & 4.29 & 4.11 & .079 & .121 & .119 \\
\hline Tests & 22 & 19 & 20 & 7.0 & 3.5 & 4.38 & .111 & .128 & .109 \\
\hline
\end{tabular}


tral and organizing theme underlying the discussion of all of the items within the context of obstacles to care. In addition, the quality of this communication was described as a motivator for or an obstacle to prenatal care for women in every focus group. Because of the dominance of this theme, we concentrate on this area for the remaining analysis.

\section{Communication With Clinicians}

Women in both low- and higher-literacy groups described communication in relation to an idealized model in which questions and answers flowed easily, accurately, and completely between patient and clinician (Figure 2). Ideally, patient and clinician were viewed as communication partners, each asking questions and making statements that are then accurately and completely responded to by the other. Participants contrasted this idealized model with shortcomings in their own experiences. Four clinician characteristics that influence communication effectiveness emerged: clarity, continuity of care, trust, and close patient-physician relationship (Supplemental Appendix 3, available online-only at http:/www.annfammed.org/cgi/ content/full/4/4/334/DC1 provides quotes for each characteristic from interview transcripts).

\section{Clarity: "Breaking It Down"}

Women in all of the groups valued physicians who provided medical information in a way that they could understand, commonly referred to as "breaking it down."

"Like, if I didn't understand something, like, I couldn't understand a word they was saying, she would break it down to me-this mean this."

Conversely, women described poor-quality clinicians as unable to provide health information in a clear, accessible form. Some women reported that they did not tell the clinician when they did not understand. Some stated a belief that their clinicians knew that they did not understand and still did nothing to help them.

"I wouldn't tell her that I didn't understand it, you know. But, you know, people know when you know, just by talking to you."

\section{DISCUSSION}

In this concurrent mixed methods study of low-income African American women, at least one half had poor use of prenatal care (late initiation and/or low numbers of visits). This high rate of poor utilization did not vary signifi-

Figure 2. Patient-derived model of patient-clinician communication.

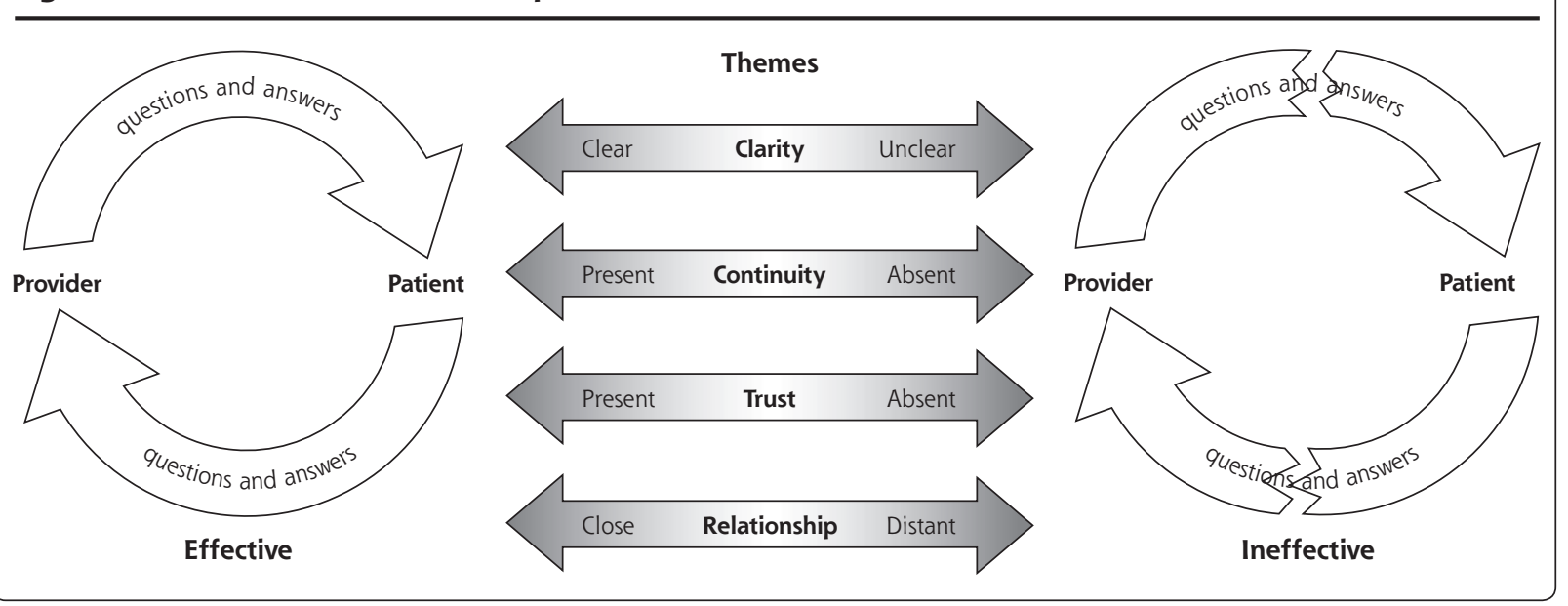


cantly by literacy level. A cultural domain relating to the experience of prenatal care was identified by CDA, which was made up of a single factor with 9 member items. Follow-up focus groups on obstacles to prenatal care both confirmed the relevance of the component items to participants with low- and higher-literacy skills and generated a linking theme, communication with clinicians, for the items of this domain. Successful communication, characterized by an idealized model of reciprocal flow of information between patient and clinician, was seen as promoting prenatal care, whereas unsuccessful communication made women less likely to come to prenatal care visits. The ability to communicate clearly by breaking down topics, to provide continuous prenatal care, to be trusted by the patient, and to have a close patient-clinician relationship were, from the patient's perspective, critical to effective patientclinician communication.

We were surprised that literacy was not associated with prenatal care utilization. The adherence to medical care by patients with chronic diseases has been shown to vary by literacy. ${ }^{24}$ The women in this sample all had very high rates of poor prenatal care, and it may be that the risk associated with low literacy is not distinguishable in that context. We were intrigued by the finding that communication with clinicians was an important theme for all of the participants in this study. At the onset we had imagined that among perceived obstacles to prenatal care, communication would be a particular issue for women of low literacy. Our data suggest that for women communication is a major theme independent of literacy skill.

The patient-derived model of ideal (desired) patient-physician communication that emerged from our analysis (Figure 1) shares important characteristics with the patient-centered communication model. ${ }^{25}$ Patient-centered communication calls for the clinician to elicit and understand the patient's perspective and context, strive to create a shared understanding of the medical problem that is in alignment with the patients values, and facilitate active participation and partnership in the medical care. Patient-centered communication is linked to better medical adherence and outcomes and is considered a component of high-quality health care. ${ }^{26,27}$ Poor patient-clinician communication has been identified as an important contributor to disparities in health care and health care quality. 1,28,29 The quality of patient-clinician communication is associated with patient satisfaction and with risk of malpractice claims for physicians, including obstetric clinicians. ${ }^{30,31}$ The quality of the patient-clinician relationship has also been suggested to promote prenatal care adherence. ${ }^{32}$ Our study complements this work and extends it by identifying the value of the com- munication process from the perspective of women in prenatal care and with varying literacy. We have also identified "breaking it down," or providing information with clarity in simple pieces, as a specific clinician characteristic valued by patients.

This study is limited by a small sample size, and significant differences in use of care related to literacy may be found in future larger studies. Our power analysis indicated that to find a significant difference in utilization based on the current findings would require a sample of more than 900 . There may be additional important themes that would emerge through further qualitative investigation. An iterative sequential design for this mixed methods study would have provided more assurance that the themes we identified exhausted those relevant to the topic (saturation of themes). Our use of non-African American interviewers may have limited discussion of such issues as race discordance between patients and clinicians as obstacles to care. These limitations, however, do not diminish the value of the themes we identified, particularly the role of poor patient-clinician communication as a perceived obstacle to care utilization in this vulnerable population

Our results indicate that improving the clarity of communication, described as "breakin' it down," with prenatal patients is an important goal for maternal care clinicians. Interventions to improve communication skills for clinicians should explicitly teach this skill, in addition to those of patient-centered communication. Because patients of both low and higher literacy endorse the value of these clinician characteristics, all patients should benefit from such efforts. Further research is needed to determine whether interventions focused on this approach will improve use of prenatal care and whether the effects of interventions vary by patient literacy.

To read or post commentaries in response to this article, see it online at http://www.annfammed.org/cgi/content/full/4/4/334.

Key words: Communication barriers; patient-physician relations; educational status; literacy; maternal health services; prenatal care; low income population; pregnancy

Submitted September 1, 2005; submitted, revised, November 22, 2005; accepted January 30, 2006.

Funding support: This research was supported by a grant to Dr Bennett from the University of Pennsylvania Research Foundation. Dr Bennett is a Pfizer Health Literacy Scholar.

Portions of this work have been presented at the 2004 North American Primary Care Research Group Annual Meeting, Banff, Alberta, Canada.

Acknowledgments: Thanks to Carol Petraitis and Princess Skyers for help with the reported research and manuscript preparation. 


\section{References}

1. National Healthcare Disparities Report. Rockville, MD: Department of Health and Human Services, Agency for Healthcare Research and Quality; 2003.

2. Data 2010: the healthy people 2010 database. Hyattsville, MD: US Department of Health and Human Services, CDC, National Center for Health Statistics; 2004. Available at: http://wonder.cdc.gov/ data2010/focus.htm

3. US Department of Health and Human Services. Healthy People 2010. With Understanding and Improving Health and Objectives for Improving Health. 2nd ed. Washington, DC: US Government Printing Office; 2000

4. Fiscella K. Does prenatal care improve birth outcomes? A critical review. Obstet Gynecol. 1995;85:468-479.

5. Goldenberg RL, Rouse DJ. Prevention of premature birth. N Engl J Med. 1998;339:313-320.

6. Klerman LV, Ramey SL, Goldenberg RL, et al. A randomized trial of augmented prenatal care for multiple-risk, Medicaid-eligible African American women. Am J Public Health. 2001;91:105-111.

7. Lu MC, Tache V, Alexander GR, Kotelchuck M, Halfon N. Preventing low birth weight: is prenatal care the answer? J Matern Fetal Neonatal Med. 2003;13:362-380.

8. York R, Tulman L, Brown K. Postnatal care in low-income urban African American women: relationship to level of prenatal care sought. J Perinatol. 2000;20:34-40.

9. Nielsen-Bohlman L, Panzer AM, Kindig D, eds. Health Literacy: A Prescription to End Confusion. Committee on Health Literacy, Board on Neuroscience and Behavioral Health, Institute of Medicine of the National Academies. Washington, DC: National Academies Press; 2004.

10. Braveman P, Marchi K, Egerter S, Pearl M, Neuhaus J. Barriers to timely prenatal care among women with insurance: the importance of prepregnancy factors. Obstet Gynecol. 2000;95:874-880.

11. Sword W. Prenatal care use among women of low income: a matter of "taking care of self". Qual Health Res. 2003;13:319-332.

12. Davis TC, Long SW, Jackson RH, et al. Rapid estimate of adult literacy in medicine: a shortened screening instrument. Fam Med. 1993;25:391-395.

13. Moon RY, Cheng TL, Patel KM, Baumhaft K, Scheidt PC. Parental literacy level and understanding of medical information. Pediatrics. 1998; 102:e25.

14. Health literacy: report of the Council on Scientific Affairs. Ad Hoc Committee on Health Literacy for the Council on Scientific Affairs, American Medical Association. JAMA. 1999;281:552-557.

15. Kotelchuck M. An evaluation of the Kessner Adequacy of Prenatal Care Index and a proposed Adequacy of Prenatal Care Utilization Index. Am J Public Health. 1994;84:1414-1420.

16. Romney A. Cultural Consensus as a statistical model. Curr Anthropol. 1999:40:S103-115.

17. Borgatti SPEM. Models of core/periphery structures. Soc Networks. $1999 ; 21: 375-395$.
18. ANTHROPAC 4.0 Methods Guide. Version 4.0. Natick, Mass: Analytic Technologies; 1996.

19. Curry MD, Mathews HF, Daniel HJ, 3rd, Johnson JC, Mansfield CJ. Beliefs about and responses to childhood ear infections: a study of parents in eastern North Carolina. Soc Sci Med. 2002;54:1153-1165.

20. Dressler W, Oths KS. Cultural determinants of health behavior. In: Gochman D, ed. Handbook of Health Behavior Research I: Personal and Social Determinants. New York, NY: Plenum Press; 1997:359-378.

21. Dressler WW, Balieiro MC, Ribeiro RP, Ernesto Dos Santos J. Cultural consonance and arterial blood pressure in urban Brazil. Soc Sci Med. 2005;61:527-540.

22. Glaser B. The Discovery of Grounded Theory: Strategies for Qualitative Research. Chicago, III: Aldine; 1967

23. Creswell JWPCV, Guttman M, Hanson W. Advanced mixed methods research design. In: Tashakkori A, Teddlie C, eds. Handbook of Mixed Methods in Social and Behavioral Research. Thousand Oaks, Calif: Sage Publications; 2003:209-240.

24. Berkman ND, DeWalt DA, Pignone MP, et al. Literacy and Health Outcomes. Rockville, MD: Agency for Healthcare Research and Quality; 2004. AHRQ Publication No. 04-E007-2. Evidence Report/ Technology Assessment No. 87 (Prepared by RTI InternationalUniversity of North Carolina Evidence-based Practice Center under Contract No. 290-02-0016).

25. Epstein RM, Franks P, Fiscella K, et al. Measuring patient-centered communication in patient-physician consultations: theoretical and practical issues. Soc Sci Med. 2005;61:1516-1528.

26. Stewart M, Brown JB, Donner A, et al. The impact of patient-centered care on outcomes. J Fam Pract. 2000;49:796-804

27. Committee on Quality Healthcare in America. Crossing the Quality Chasm: A New Health System for the 21st Century. Washington, DC: Institute of Medicine, National Academies Press; 2001.

28. Smedley B, Stith AY, Nelson AR, eds. Unequal Treatment: Confronting Racial and Ethnic Disparities in Health Care. Committee on Understanding and Eliminating Racial and Ethnic Disparities in Health Care, Board on Health Sciences Policy, Institute of Medicine; 2003.

29. Johnson RL, Roter D, Powe NR, Cooper LA. Patient race/ethnicity and quality of patient-physician communication during medical visits. Am J Public Health. 2004;94:2084-2090.

30. Levinson W, Roter DL, Mullooly JP, Dull VT, Frankel RM. Physicianpatient communication. The relationship with malpractice claims among primary care physicians and surgeons. JAMA. 1997;277: 553-559.

31. Hickson GB, Clayton EW, Entman SS, et al. Obstetricians' prior malpractice experience and patients' satisfaction with care. JAMA. $1994 ; 272: 1583-1587$

32. Campbell JD, Mitchell P, Stanford JB, Ewigman BG. Validating a model developed to predict prenatal care utilization. J Fam Pract. 1995:41:457-464. 